\title{
COMPARATIVE STUDY BETWEEN LICHTENSTEIN TENSION-FREE AND MODIFIED BASSINI'S REPAIR FOR INGUINAL HERNIAS
}

\author{
Sudhir Suresh Bhat ${ }^{1}$
}

${ }^{1}$ General Surgeon, Department of General Surgery, JJMMC, Davangere, Karnataka.

\begin{abstract}
BACKGROUND

Inguinal hernia repair is the most frequently performed operation in any general surgical unit. Reports on the outcome of inguinal hernia surgery show that recurrence rate in 5 years after operation can vary from $0.1 \%$ to over $20 \%$. The aim of the present study is to compare Lichtenstein tension-free hernia repair with the Modified Bassini's herniorrhaphy in terms of immediate complications like technical difficulty, seroma formation, wound infection rate, recurrence rate at one year and chronic pain.
\end{abstract}

\section{MATERIALS AND METHODS}

100 cases admitted to Chigateri General Hospital and Bapuji Hospital, attached to JJM Medical College, Davangere from June 2009 to May 2011 with primary unilateral inguinal hernia were randomly selected using SAS software subjected either to Modified Bassini's herniorrhaphy or Lichtenstein hernioplasty. All the hernia repairs were performed under spinal anaesthesia. In case, any associated conditions like hypertension, diabetes mellitus were present, treatment was first given for these associated conditions. A note was taken of any technical difficulty during surgery. The patients were followed in the surgical OPD at 1 month, 6 months and 1 year for time taken to return to normal activities, chronic groin pain, patient's satisfaction and recurrence.

\section{RESULTS}

Technical difficulty was encountered in 4 patients (i.e. 8\%) undergoing Modified Bassini's herniorrhaphy. No technical difficulty was encountered in any of the patients in Lichtenstein group. At 1 month followup, 20 patients (i.e. 40\%) of Modified Bassini's herniorrhaphy group patients had mild pain whereas 14 patients (i.e. 28\%) had mild pain in the Lichtenstein group. However, none of the patients in any of the two groups had any degree of pain at 6 months and 1 year. There was one recurrence (i.e. 2\%) in Modified Bassini's herniorrhaphy. However, no recurrence was seen in Lichtenstein group. Time to return to work was relatively shorter in Lichtenstein group.

\section{CONCLUSION}

Lichtenstein is an easy, straightforward technique for inguinal hernia repair with fewer recurrences, less hospital stay and less duration of surgery. However, amongst the pure tissue repairs Modified Bassini's herniorrhaphy still remains relevant.

\section{KEYWORDS}

Inguinal Hernia, Prolene Mesh, Mesh Versus Non-mesh, Tension-free Repair, Modified Bassini's Herniorrhaphy Versus Lichtenstein Hernioplasty.

HOW TO CITE THIS ARTICLE: Bhat SS. Comparative study between Lichtenstein tension-free and modified Bassini's repair for inguinal hernias. J. Evolution Med. Dent. Sci. 2017;6(45):3503-3506, DOI: 10.14260/Jemds/2017/756

\section{BACKGROUND}

Hernia is the word derived from Greek word 'Herons' means 'offshoot' or 'bulge' or 'budding'. In Latin, it means 'tear' or 'rupture'. It is defined by Sir Astley Cooper as "a protrusion of any viscus from its proper cavity". ${ }^{1}$ Inguinal hernia repair is the most frequently performed operation in any general surgical unit. Reports on the outcome of inguinal hernia surgery shows that recurrence rate 5 years after operation can vary from 0.1 to over $20 \%$. Present day hernia operations require that a herniologist fully understand the functional anatomy and pathophysiology of the abdominal wall, the inguinal and the femoral canals. ${ }^{2}$

Financial or Other, Competing Interest: None.

Submission 21-04-2017, Peer Review 24-05-2017,

Acceptance 30-05-2017, Published 05-06-2017.

Corresponding Author:

Dr. Sudhir Suresh Bhat,

\#2090/B, Koregalli,

Shahapur,

Belgaum-590003.

Karnataka.

E-mail:drsudhirbhat@gmail.com

DOI: $10.14260 /$ jemds $/ 2017 / 756$
Hernia surgeons must be familiar with a myriad of surgical techniques ranging from the traditional sutured to the mesh based tension-free to the laparoscopic repair. The hernia surgeon must understand the science of prosthetic materials and should know how to recognise them and treat all manners of complications, from a patient with an infected mesh to those suffering from supposed mesh-induced neuralgia. ${ }^{3}$

The Modified Bassini's repair is easier to learn, cheaper in terms of initial costs and more commonly used in hospitals. ${ }^{4}$ The Lichtenstein tension-free repair opened a new era in groin hernia repair. ${ }^{5}$ In terms of recurrence rates and patient centred outcomes, it has become the gold standard of groin hernia repair.

The aim of the present study is to compare Lichtenstein tension-free hernia repair with the Modified Bassini's herniorrhaphy in terms of immediate complications like technical difficulty, seroma formation, wound infection rate, recurrence rate at one year and chronic pain.

\section{MATERIALS AND METHODS}

This is a randomised controlled trial study in which patients presenting with of unilateral primary uncomplicated indirect 
and direct inguinal hernias in Bapuji Hospital and Chigateri District Hospital will be taken into study-

1. The period of study is from June 2009 to May 2011.

2. A total of 100 cases undergoing hernia repair are allocated randomly using SAS software to each study group as follows-

a) Group I- Modified Bassini's repair - 50 cases.

b) Group II- Lichtenstein hernia repair - 50 cases.

The diagnosis of unilateral primary uncomplicated indirect and direct inguinal hernia was made on basis of history of reducible groin swelling and essentially on clinical examination, appropriate laboratory and radiological investigations and followup of the cases.

Only those investigations were done which were relevant to obtain fitness for surgery. This included $\mathrm{Hb} \%$, BT, CT, RBS, Blood urea, Serum creatinine, ECG, and routine urine analysis for sugar, albumin and microscopy, HIV, HbsAg, chest x-ray and ultrasound abdomen. If any patient was found to have any medical contraindication for surgery, he was first treated for these medical problems and then re-evaluated for surgery. All were performed under spinal anaesthesia using $3 \mathrm{~mL}$ of bupivacaine 2\% (Sensorcaine).

The subjects will be selected for the study consecutively as and when they are presented with following inclusion and exclusion criteria.

\section{Inclusion Criteria}

1. Men 20 years of age or older with unilateral primary inguinal hernia.

2. Patients who gave consent for the procedure.

\section{Exclusion Criteria}

1. Recurrent hernias.

2. Presence of bowel obstruction, strangulation, peritonitis or perforation.

3. Patients medically unfit for surgery.

Selection of operative procedure was done by the operating surgeon randomly. In Lichtenstein hernioplasty, a 3 inch $\mathrm{x} 6$ inch polypropylene mesh made by Ethicon company was used. The mesh is $-0.5 \mathrm{~mm}$ thick and has a burst strength of approximately $14 \mathrm{~kg} / \mathrm{cm}^{2}$. It is sterilised by Ethylene oxide gas by the manufacturer.

Polypropylene 2-0 was used to suture the mesh in place. Similarly, for Modified Bassini's repair, polypropylene 2-0 was used for suturing double breasted layers of Transversalis fascia and suturing conjoined tendon to inguinal ligament in two layers and extracanalisation of spermatic cords done. The note was taken of the contents of the sac, duration of surgery and any technical difficulty encountered during the surgery.

Postoperatively, patient was put on Inj. Cefotaxime $1 \mathrm{~g}$ BD intravenously for seven days and Inj. Diclofenac $75 \mathrm{mg}$ IM BD for 3 days with one shot of Inj. Diclofenac being given 3 hours after surgery (evening dose).

The patients were followed up for postoperative pain which was evaluated using Visual Analogue Scale, wound haematoma, wound seroma, wound infection. Sutures were removed on the 7 th postoperative day and the patients discharged if there was no wound infection, were ambulatory, were taking orally and felt comfortable. Patients were called to the outpatient department and followup was done for complications like chronic groin pain (inguinodynia), testicular atrophy, time taken to resume normal activity, patient's satisfaction and recurrence.

\section{Followup}

1. Immediate complications: Seroma formation, wound infection rate, pain and recurrence.

2. Late complications: Chronic pain, recurrence.

\section{Patient Satisfaction}

Patients at the time of discharge as well as during followup were asked about their experience of surgery both intraoperative and post-operative. The physical function, any limitation caused by physical problems due to surgery, social function and vitality were assessed. Each patient was specifically asked whether he would like to undergo the same procedure in case of development of hernia on opposite side and whether he would recommend the same procedure to other patients with such problems. Each patient was specifically asked whether he was satisfied with the quality of life he was leading after the surgery.

\section{Time to Return to Normal Activity}

All patients were encouraged to return to work as soon as possible, patient in both the groups were followed and the post-operative time period that elapsed between day of surgery and the day of joining of duty at their work place was recorded and compared.

\section{Testicular Atrophy}

Any tenderness in the testis on the same side of surgery in post-operative period was recorded. Similarly, any decrease in size of the testicle of the same side was recorded.

\section{Recurrence}

Patients were followed for recurrence. Recurrence was defined as clinically manifest bulge or a protrusion exacerbated by Valsalva manoeuvre in the operated groin. Hernial recurrence and death of the patient were considered as end points.

\section{RESULTS}

The present study was carried out in the Department of Surgery in Chigateri General Hospital and Bapuji Hospital attached with JJM Medical College at Davangere. 100 cases of unilateral primary inguinal hernia were included in the study after taking their consent. They were subjected to Lichtenstein or Modified Bassini's methods of hernia repair. Evaluation of all the patients included in the study was done regarding the history, physical findings, operative findings and postoperative complications. 50 patients underwent repair with Prolene mesh and 50 patients underwent Modified Bassini's herniorrhaphy. All the cases in both the groups were followed for a period of one year. The patients were followed up at one monthly, six monthly and yearly intervals for any complication or recurrence. Any recurrence of hernia or death of patient was considered an end point. Analysis of results done using Independent $t$ test, Chi square test and Fischer test. 


\begin{tabular}{|c|c|c|}
\hline $\begin{array}{l}\text { Age Group } \\
\text { (years) }\end{array}$ & $\begin{array}{c}\text { Modified } \\
\text { Bassini's n (\%) }\end{array}$ & $\begin{array}{c}\text { Lichtenstein } \\
\text { n (\%) }\end{array}$ \\
\hline $20-29$ & $2(4)$ & $7(14)$ \\
\hline $30-39$ & $7(14)$ & $11(22)$ \\
\hline $40-49$ & $11(22)$ & $10(20)$ \\
\hline $50-59$ & $12(24)$ & $11(22)$ \\
\hline $60-69$ & $14(28)$ & $8(16)$ \\
\hline Total & 50 & 50 \\
\hline Age range (years) & $20-80$ & $20-72$ \\
\hline \multicolumn{3}{|c|}{ Table 1. Comparison of Age wise Distribution of Cases } \\
\hline
\end{tabular}

\begin{tabular}{|c|c|c|}
\hline Symptoms & $\begin{array}{c}\text { Modified } \\
\text { Bassini's n (\%) }\end{array}$ & $\begin{array}{c}\text { Lichtenstein } \\
\text { n (\%) }\end{array}$ \\
\hline Swelling & $50(100)$ & $50(100)$ \\
\hline Pain & $23(46)$ & $23(46)$ \\
\hline Table 2. Comparison of Associated Symptoms \\
\hline
\end{tabular}

In both of the groups, all patients presented with swelling in the groin (100\%) and pain was present in 23 cases (46\%) of patients in each group.

\begin{tabular}{|c|c|c|c|c|}
\hline \multirow{2}{*}{ Duration } & \multicolumn{2}{|c|}{$\begin{array}{c}\text { Modified Bassini's } \\
\text { n (\%) }\end{array}$} & \multicolumn{2}{c|}{$\begin{array}{c}\text { Lichtenstein } \\
\text { n (\%) }\end{array}$} \\
\cline { 2 - 5 } & Swelling & Pain & Swelling & Pain \\
\hline$<1$ month & - & - & - & - \\
\hline $1-6$ months & $15(30)$ & 6 & $21(42)$ & 3 \\
\hline $6-12$ months & $7(14)$ & 3 & $19(38)$ & 9 \\
\hline $\begin{array}{c}12 \text { months }- \\
2 \text { years }\end{array}$ & $8(16)$ & 2 & $4(8)$ & - \\
\hline 2 years + & $17(34)$ & 2 & $6(12)$ & - \\
\hline Total & $50(100)$ & 13 & $50(100)$ & 13 \\
\hline Range & $1 \mathrm{~m}-6 \mathrm{y}$ & $1 \mathrm{~m}-2 \mathrm{y}$ & $1 \mathrm{~m}-4 \mathrm{y}$ & $3 \mathrm{~d}-3 \mathrm{y}$ \\
\hline Table 3. Comparison of Duration of Symptoms \\
\hline \multicolumn{7}{|c}{}
\end{tabular}

A majority of patients in both groups presented with duration of swelling for 1-6 months. Similarly, majority of the patients in both groups presented with duration of pain of 1 6 months.

\begin{tabular}{|c|c|c|}
\hline Side & Modified Bassini's n (\%) & Lichtenstein n (\%) \\
\hline Right & $41(82)$ & $32(64)$ \\
\hline Left & $9(18)$ & $18(36)$ \\
\hline Total & $\mathbf{5 0}(\mathbf{1 0 0})$ & $\mathbf{5 0}(\mathbf{1 0 0 )}$ \\
\hline \multicolumn{3}{|c|}{ Table 4. Comparison of Side Affected } \\
\hline
\end{tabular}

\begin{tabular}{|c|c|c|}
\hline & Modified Bassini's n (\%) & Lichtenstein n (\%) \\
\hline Indirect & $40(80)$ & $31(62)$ \\
\hline Direct & $10(20)$ & $19(38)$ \\
\hline Total & $\mathbf{5 0}(100)$ & $\mathbf{5 0}(\mathbf{1 0 0})$ \\
\hline \multicolumn{2}{|r|}{ Table 5. Comparison of Direct/Indirect Hernia } \\
\hline
\end{tabular}

A majority of inguinal hernias in both the groups were right sided and a majority of sacs found were indirect in both the groups.

\begin{tabular}{|c|c|c|}
\hline $\begin{array}{c}\text { Associated } \\
\text { Factors }\end{array}$ & $\begin{array}{c}\text { Modified Bassini's } \\
\text { n (\%) }\end{array}$ & $\begin{array}{c}\text { Lichtenstein } \\
\text { n (\%) }\end{array}$ \\
\hline Smoking & $24(48)$ & $19(38)$ \\
\hline BEP & $3(6)$ & $4(8)$ \\
\hline DM & $5(10)$ & $2(4)$ \\
\hline HTN & $10(20)$ & $12(24)$ \\
\hline BA & - & $1(2)$ \\
\hline Total & $\mathbf{5 0 ( 1 0 0 )}$ & $\mathbf{5 0}(100)$ \\
\hline \multicolumn{2}{|c|}{ Table 6. Comparison of Associated Factors } \\
\hline
\end{tabular}

The most common factor associated with inguinal hernia in both the groups was smoking.

\begin{tabular}{|c|c|c|c|c|}
\hline Groups & Range & Mean \pm SD & $\mathbf{t}^{*}$ & $\mathbf{p}$ \\
\hline $\begin{array}{c}\text { Modified } \\
\text { Bassini's }\end{array}$ & $40-75 \mathrm{~min}$ & $65.8 \pm 6.4$ & & \\
\hline Lichtenstein & $30-50 \mathrm{~min}$ & $41.8 \pm 5.6$ & 20.6 & $<0.001, \mathrm{HS}$ \\
\hline \multicolumn{2}{|l}{ Table 7. Comparison of Duration of Surgery (min) } \\
\hline
\end{tabular}

Table 7. Comparison of Duration of Surgery (min.)

*unpaired t-test.

Duration of surgery in case of Lichtenstein hernioplasty was significantly less than duration of surgery in modified Bassini's herniorrhaphy.

\begin{tabular}{|c|c|c|}
\hline & Modified Bassini's n (\%) & Lichtenstein n (\%) \\
\hline Yes & $4(8)$ & - \\
\hline No & $46(92)$ & $50(100)$ \\
\hline \multicolumn{3}{|c|}{ Table 8. Comparison of Technical Difficulty } \\
\hline
\end{tabular}

Fisher's exact test, $p=0.24$, NS ( $p>0.05)$.

Technical difficulty was encountered in 4 patients in modified Bassini's group accounting for $8 \%$ of patients in the present study group. No technical difficulty was encountered in Lichtenstein hernioplasty group.

\begin{tabular}{|c|c|c|}
\hline & Modified Bassini's n (\%) & Lichtenstein n (\%) \\
\hline Haematoma & $1(2)$ & 0 \\
\hline Seroma & $4(8)$ & $2(4)$ \\
\hline Infection & $5(10)$ & $4(8)$ \\
\hline Normal & $40(80)$ & $44(88)$ \\
\hline Total & $\mathbf{5 0 ( 1 0 0 )}$ & $\mathbf{5 0}(100)$ \\
\hline \multicolumn{2}{|c|}{ Table 9. Comparison of Immediate Postoperative } \\
Complications - Haematoma/Seroma/Infection \\
\hline
\end{tabular}

Immediate post-operative complications were less in Lichtenstein group (12\%) as compared to Modified Bassini's (20\%).

\begin{tabular}{|c|c|c|c|c|}
\hline Groups & $\begin{array}{c}\text { Range } \\
\text { (Days) }\end{array}$ & Mean \pm SD & $\mathbf{t}^{*}$ & $\mathbf{p}$ \\
\hline $\begin{array}{c}\text { Modified } \\
\text { Bassini's }\end{array}$ & $10-14$ & $11.5 \pm 1.3$ & & \\
\hline Lichtenstein & $5-12$ & $8.7 \pm 2.1$ & 8.01 & $<0.001, \mathrm{HS}$ \\
\hline
\end{tabular}

Table 10. Comparison of Time Taken to Resume Normal Activities or Convalescence Period

* unpaired t-test.

Time taken to resume normal activities was significantly less in case.

There was no case of testicular atrophy in either of the study groups.

\begin{tabular}{|c|c|c|}
\hline & Modified Bassini's n (\%) & Lichtenstein n (\%) \\
\hline Yes & $48(96)$ & $50(100)$ \\
\hline No & $2(4)$ & - \\
\hline \multicolumn{2}{|c|}{ Table 11. Comparison of Patient Satisfaction } \\
\hline
\end{tabular}




\begin{tabular}{|c|c|c|c|c|}
\hline \multirow{2}{*}{ Duration } & \multicolumn{2}{|c|}{ Modified Bassini's n (\%) } & \multicolumn{2}{c|}{ Lichtenstein n (\%) } \\
\cline { 2 - 5 } & Yes & No & Yes & No \\
\hline$<1$ month & - & $50(100)$ & - & $50(100)$ \\
\hline 6 months & $2(4)$ & $48(96)$ & - & $50(100)$ \\
\hline 1 year & $1(2)$ & $49(98)$ & - & $50(100)$ \\
\hline \multicolumn{3}{|c|}{ Table 12. Comparison of Recurrence } \\
\hline
\end{tabular}

Numbers in parenthesis indicate percentages.

1 patient in Modified Bassini's group (2\%) had a recurrence after one year.

Whereas none of patients in Lichtenstein group had a recurrence.

\section{DISCUSSION}

All inguinal hernias share the common feature of emerging through the myopectineal orifice of Fruchaud, the opening in the lower abdominal wall bounded above by the myoaponeurotic arch of the lower edges of the Internal Oblique and the Transverses Abdominis, muscle, and below by the pectineal line of the superior pubic ramus. It serves as a passage for the blood vessels, nerves, lymphatics, muscle and tendons between the abdomen and lower limb. The treatment of inguinal hernias has evolved over the past 150 years from truss support with operation reserved for life threatening situations to elective outpatient surgery. Currently, two major techniques of hernia repair exist-

1. Pure tissue repairs.

2. Tension-free or mesh repairs.

Pure tissue repairs involve approximating of the defect edges. Hence, these repairs have suture lines which are under tension after the repair. Excessive tension on the suture line and surrounding tissues leads to tissue ischaemia and suture cut-out leading to recurrence. Tension-free or mesh repairs involve the use of synthetic mesh to strengthen the posterior wall. Since the defect edges are not approximated but just bridged using mesh, there is a tension less repair. ${ }^{6}$

Our patients want their postoperative periods to be uncomplicated and short so as to return to their normal daily activities. Similarly, surgeons want techniques with short learning curves and their recurrence rates comparable with specialist centres. There is little doubt that modified Bassini's herniorrhaphy is technically more demanding than mesh repair.

The present comparative study is a small study and followup is limited for a period of one year. Therefore, this is a limitation of this study. Amongst the 50 patients subjected to Modified Bassini's herniorrhaphy, one patient had developed recurrence when followed up 1 year after surgery. The man aged 72 years was a chronic smoker and hypertensive. He had a recurrence of left indirect inguinal hernia. Technical difficulty due to thinning of Transversalis fascia was also encountered in this patient during the surgery. Among the 50 cases subjected for Lichtenstein hernioplasty, none had recurrence.

\section{CONCLUSION}

Both Modified Bassini's and Lichtenstein types of hernia repair are comparable and effective methods of hernia repair. The
Modified Bassini's technique involves more dissection than Lichtenstein hernioplasty. As Modified Bassini's technique involves dissecting and strengthening of the Transversalis fascia, technical difficulty may arise in case of older patients as the fascia is thinned out. Modified Bassini's herniorrhaphy requires time to master the technique. Compared to it, Lichtenstein hernioplasty is technically easier to learn and likely to lead to fewer recurrences.

However, amongst the pure tissue repairs, Modified Bassini's herniorrhaphy still remains relevant in the armamentarium of inguinal hernia repair.

\section{Summary}

- This was a comparative study comprising hundred patients having primary unilateral inguinal hernia. 50 patients were subjected to Modified Bassini's herniorrhaphy. Similarly, 50 patients were subjected to Lichtenstein hernioplasty.

- The patients presented with swelling in the groin with duration ranging from 15 days to 6 years. Highest number of patients were in the age group 40-69 in the Modified Bassini's group. Similarly, highest number of patients were in the age group 30-59 in the Lichtenstein group.

- Smoking was the most common associated factor present in both groups.

- During the surgery, no technical difficulty was encountered in Lichtenstein group.

- $\quad$ Lichtenstein hernioplasty takes less time for surgery as compared to Modified Bassini's herniorrhaphy.

- In both groups, none of the patients had chronic groin pain at 1 year of followup.

- $\quad$ Lichtenstein group of patients take less time to return to normal activities as compared with Modified Bassini's group.

- No recurrence was noted in any of the patients in the Lichtenstein group at 1 year.

\section{REFERENCES}

[1] Skandalakis JE, Gray SW, Ricketts R, et al. The anterior abdominal wall. In: Skandalakis JE, Gray SW, (eds). Embryology for surgeons-the embryological basis for the treatment of congenital anomalies. Maryland, USA: Williams and Wilkins 2003;83:1019-287.

[2] Snell RS. Clinical anatomy for medical students. $3^{\text {rd }}$ edn. Boston: Little, Brown and Company, 1986.

[3] Dorairajan N. Inguinal hernia-yesterday, today and tomorrow. Ind J Surg 2004;66(3):137-9.

[4] Check C, Kingsmorth A. Inguinal and femoral hernia. In: Morres PJ, Wood WC, (eds). Oxford textbook of surgery. $2^{\text {nd }}$ edn. London: Oxford University Press, 2000.

[5] Kurzer M, Belsham PA, Kark AE. The Lichtenstein repair for groin hernias. Surg Clin North Am 2003;83(5):1099-117.

[6] Abrahamson J. Hernias. Chapter 14. In: Zinner MJ, Schwartz SI, Ellis H, (eds). Maingot's abdominal operations. USA: Appleton and Lange 1997:pp 479. 